\title{
Duration of Biphoshonate Therapy in Osteoporosis: Where Do We Stand Today?
}

\author{
Hande Mefkure Ozkaya* \\ Department of Endocrinology and Metabolism, University of Health Sciences, Turkey
}

Received: February 13, 2018; Published: February 26, 2018

*Corresponding author: Hande Mefkure Ozkaya, Department of Endocrinology and Metabolism, Okmeydani Training and Research Hospital, University of Health Sciences, 34384, Okmeydani, Istanbul, Turkey, Tel: 90- 212 -314 55 55; Fax: 90-212- 22178 00; Email: hndebektas@gmail.com

\begin{abstract}
Despite recent advances in treatment of osteoporosis and the availability of new agents bisphosphonates are still the cornerstone of osteoporosis treatment due to their safety, efficacy and relatively reasonable costs. On the other hand, the presence of rare side effects has brought to the agenda that these drugs should be given during limited time periods. The current approach is to perform dynamic risk identification in patients and to determine the type and duration of the treatment accordingly.
\end{abstract}

Keywords: Biphosphonate; Osteoporosis; Safety

Abbreviations: FIT: Fracture Intervention Trial; BMD: Bone Mineral Density; VERT: The Vertebral Efficacy with Risedronate Therapy; FDA: Food and Drug Administration; FLEX: The Fracture Intervention Trial Long term extension

\section{Introduction}

Fragility fractures due to osteoporosis are seen in approximately $30 \%$ of females and $20 \%$ of males over the age of 50 [1]. Each fragility fracture increases the risk of re-fracture, more pronounced in males than females. Mortality due to major or recurrent minor fractures is increasing, especially in later ages [2-4]. This risk continues for up to 5 to 10 years after the fracture [3]. Early diagnosis and effective treatment of osteoporosis is therefore important. On the other hand, optimal treatment duration and potential benefits and harms of long-term therapy remain still unknown.

\section{Efficacy and Side Effects of Biphosphonates}

Biphosphonates are widely prescribed therapeutic agents due to their relative low cost, safety data and efficacy. Alendronate, risedronate, ibandronate and zoledronic acid are the main bisphosphonates in use [1,5-7]. Data in regard to fracture reduction of bisphosphonates came mainly of two large, randomized, placebo-controlled trials: the Fracture Intervention Trial (FIT) [8] for alendronate and the Health Outcomes and Reduced Incidence with Once Yearly Zoledronic Acid Pivotal Fracture Trial (HORIZON) [9] for zoledronic acid which both showed an increase in bone mineral density (BMD) and a decrease in fracture risk following 5 years of therapy with alendronate and three years of therapy with zoledronic acid. The Vertebral Efficacy with Risedronate Therapy (VERT) study revealed similar findings for risedronate [10].
Although ibandronate has been shown to reduce vertebral fracture, no data exist in regard to hip fracture reduction risk with Ibandronate use [11]. Despite known efficacy of biphosphonates some concerns about potential side effects, mainly atypical femoral fractures and osteonecrosis of jaw have limited their use during prolonged time periods $[1,12,13]$. Although the incidence and absolute risk of these side effects is fairly low, the American Food and Drug Administration (FDA) has added a warning sign to the prescription information of bisphosphonates pointing to the fact that optimal treatment duration is not known and each individual patient should be reassessed on the need of ongoing therapy [1]. Many osteoporosis foundation have proposed recommendations and the concept of drug holiday has come to attention $[1,7,12]$.

\section{How to Decide to the Duration of Therapy}

Indeed two extension studies have been performed to clarify the optimal duration of therapy. The Fracture Intervention Trial Long term Extension (FLEX) trial was an extension study of FIT in which a large number of postmenopausal women who had already received alendronate during 5 years were randomly assigned to receive either alendronate or placebo [14]. Patients with femoral $\mathrm{t}$ score $<-3.5$ or those with $\mathrm{t}$ score value below the FIT baseline were excluded. Patients who received an additional five years of alendronate have lost less BMD and the incidence of clinical vertebral fracture was lower. 
On the other hand the rate of morph metric vertebral, nonvertebral and hip fracture was similar between the two groups. A gradual decline of BMD was seen in patients randomized to placebo. This decline was then stabilized and BMD remained above the baseline. Another extension trial was Horizon extension trial which showed a greater loss in femoral BMD and an increase in morph metric vertebral fracture rate in patients randomized to placebo after receiving three consecutive yearly injections of zoledronic acid in comparison to those who received an additional three years of therapy [15]. Subgroup analyses showed that low femoral BMD ( $t$ score $<-2.5$ ) and incident vertebral fracture before or during study were the factors predicting future fracture risk.

\section{Conclusion}

In the light of these findings, the current recommendation is to stop bisphosphonate therapy in patients with low risk factors (i.e. $t$ score <-2.5, without a history of fracture) after 5 years of therapy with alendronate or risedronate and 3 years of therapy with zoledronic acid. The need for restarting therapy should be reassessed and individual risk factors should be re evaluated every 2-3 years. For those who are in the high risk group treatment up to 10 years with alendronate, 7 years with risedronate and 6 years with zoledronic acid would prove to be beneficial without increasing side effects $[1,7,12,14-16]$.

\section{References}

1. Adler RA, El-Hajj Fuleihan G, Bauer DC, Camacho PM, Clarke BL, et al. (2016) Managing Osteoporosis in Patients on Long-Term Bisphosphonates Treatment: Report of a Task Force of the American Society for Bone and Mineral Research. J Bone Miner Res 31(1): 16-35.

2. Peng J, Liu Y, Chen L, Peng K, Xu Z, et al. (2016) Bisphosphonates can prevent recurrent hip fracture and reduce the mortality in osteoporotic patient with hip fracture: A meta-analysis. Pak J Med Sci 32(2): 499-504.

3. Sattui SE, Saag KG (2014) Fracture mortality: associations with epidemiology and osteoporosis treatment. Nat Rev Endocrinol 10(10): 592-602.

4. Leszczynski P (2010) Zoledronic acid reduces risk of any new clinical fracture and risk of death after surgical repair of a low-trauma hip fracture. Chir Narzadow Ruchu Ortop Pol 75(3): 168-171.
5. Maraka S, Kennel KA (2015) Bisphosphonates for the prevention and treatment of osteoporosis. Bmj 351: h3783.

6. Komm BS, Morgenstern D, L AY, Jenkins SN (2015) The safety and tolerability profile of therapies for the prevention and treatment of osteoporosis in postmenopausal women. Expert Rev Clin Pharmacol 8(6): 769-784.

7. Gatti D, Adami S, Viapiana O, Rossini M (2015) The use of bisphosphonates in women: when to use and when to stop. Expert Opin Pharmacother 16(16): 2409-2421.

8. Black DM, Thompson DE, Bauer DC, Ensrud K, Musliner T, et al. (2000) Fracture risk reduction with alendronate in women with osteoporosis: the Fracture Intervention Trial. FIT Research Group. J Clin Endocrinol Metab 85(11): 4118-4124.

9. Black DM, Delmas PD, Eastell R, Reid IR, Boonen S, et al. (2007) OnceYearly Zoledronic Acid for Treatment of Postmenopausal Osteoporosis. New England Journal of Medicine 356(18): 1809-1822.

10. Harris ST, Watts NB, Genant HK, McKeever CD, Hangartner T, et al. (1999) Effects of risedronate treatment on vertebral and nonvertebral fractures in women with postmenopausal osteoporosis: a randomized controlled trial. Vertebral Efficacy With Risedronate Therapy (VERT) Study Group. Jama 282(14): 1344-1352.

11. Maraka S, Kennel KA (2015) Bisphosphonates for the prevention and treatment of osteoporosis. BMJ: British Medical Journal pp: 351.

12. Anagnostis P, Stevenson JC (2015) Bisphosphonate drug holidays-when, why and for how long? Climacteric 18 (Suppl 2): 32-38.

13. Eiken P, Vestergaard P (2016) Treatment of osteoporosis after alendronate or risedronate. Osteoporos Int 27(1): 1-12.

14. Black DM, Schwartz AV, Ensrud KE, Cauley JA, Levis S, et al. (2006) Effects of continuing or stopping alendronate after 5 years of treatment: the Fracture Intervention Trial Long-term Extension (FLEX): a randomized trial. Jama 296(24): 2927-2938.

15. Black DM, Reid IR, Boonen S, Bucci-Rechtweg C, Cauley JA, et al. (2012) The effect of 3 versus 6 years of zoledronic acid treatment of osteoporosis: a randomized extension to the horizon-pivotal Fracture Trial (PFT). J Bone Miner Res 27(2): 243-254.

16. Moro Alvarez MJ, Neyro JL, Castaneda S (2016) [Therapeutic holidays in osteoporosis: Long-term strategy of treatment with bisphosphonates]. Med Clin (Barc) 146(1): 24-29.

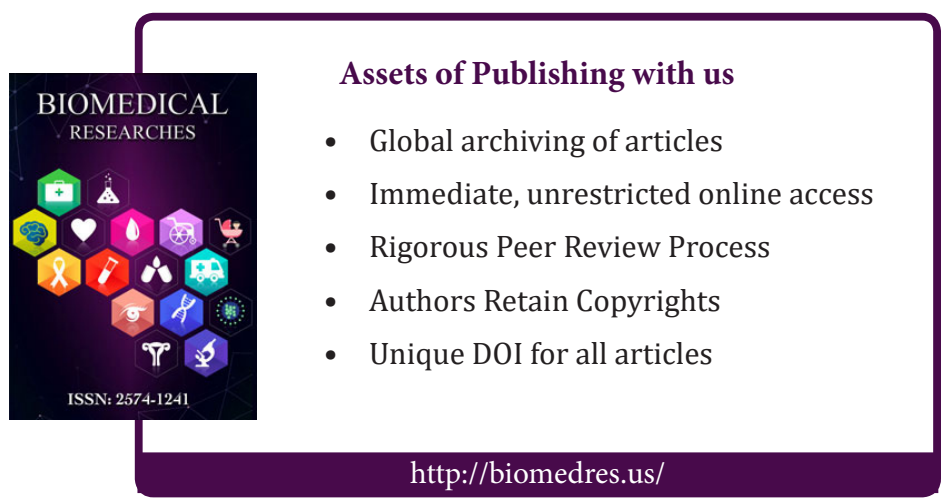

